\title{
Comparison of meperidine and fentanyl for prevention of shivering during spinal anesthesia
}

\section{Haxhire Gani*, Majlinda Naco, Vjollca Beqiri, Aurel Janko, Bilbil Hoxha and Rudin Domi}

Department of Anesthesiology and Intensive Care, UHC "Mother Teresa", Tirana (Albania)

*Corresponding Author E-mail:haxhiregani@yahoo.com

Tel.:+ 355682468280
Background: Shivering associated with spinal anesthesia is a frequent event, and the reported median incidence of shivering related to neuraxial anesthesia is up to $55 \%$ (Crowley and Buggy, 2008). The mechanism of shivering in patients undergoing spinal anesthesia is not clear, but hypothermia due to redistribution of heat caused by vasodilation below the level of a neuraxial block is suggested. Spinal anesthesia also impairs the thermoregulation system by inhibiting vasoconstriction. Shivering increases oxygen consumption, metabolic rate, lactic acidosis, carbon dioxide production, plasma catecholamines, and cardiac output. Shivering movement may interfere with monitoring of hemodynamics as well as increasing patient discomfort and distress. Therefore, it is very important to prevent shivering during spinal anesthesia.

Methods: Six hundred and fifty patients, using American Society of Anesthesiologists physical status I or II, aged 40-75 years scheduled for elective urologics surgery under spinal anesthesia were investigated. Patients with ASA physical status $>$ II, Obesity (BMI $>28 \mathrm{~kg} / \mathrm{m}^{2}$ ) Parkinson's disease, dysautonomia or Rayaud's syndrome, ischemic heart disease or cerebrovascular disease requiring blood transfusion during surgery were excluded from the study. Patients were randomly divided into two groups; Meperidine (Group $M, n=325$ ) and fentanyl (Group F, $\mathrm{n}=325$ ) groups. Group $\mathrm{M}$ and $\mathrm{F}$ received meperidine $0.4 \mathrm{mg} / \mathrm{kg}$ or fentanyl $1.5 \mathrm{mcg} / \mathrm{kg}$, respectively, in $100 \mathrm{ml}$ of isotonic saline intravenously. All drugs were infused for $15 \mathrm{~min}$ by a blinded investigator before spinal anesthesia. Blood pressures, heart rates, body temperatures and side effects were checked before, during and after spinal anesthesia.

Results: The incidences and scores of shivering were not similar between the two groups. Shivering was seen in $15(4.61 \%)$ patients who received meperidine, while in the fentanyl group, shivering occurred in 108 patients $(33.2 \%)$. In the meperidine group compared with the fentanyl group, it was seen that there is significance in preventing intraoperative and postoperative shivering in recovery without increasing the side effects $(\mathrm{P}<0.001)$. Blood pressure, body temperature and arterial oxygen saturation did not have a clinically significant change and they were not different between the two groups. Side effects of opioids were unremarkable.

Conclusion: We conclude that meperidine infusion in the periopertaive period significantly reduced shivering associated with spinal anaesthesia in urologic procedures. Meperidine is a better alternative than fentanyl for preventing shivering in patients during spinal anaesthesia $(\mathrm{P}<0.001)$.

Key words: Meperidine, fentanyl, shivering, spinal anesthesia.

\section{INTRODUCTION}

Postoperative shivering is an unpleasant side effect of recovery from anesthesia. The incidence can vary from 5 to
$60 \%$ (Crowley and Buggy, 2008) of patients after spinal anesthesia. Shivering increases oxygen consumption, 
metabolic rate, lactic acidosis, carbon dioxide production, plasma catecholamines, and cardiac output. Shivering movement may interfere with monitoring of hemodynamics as well as increasing patient discomfort and distress. Therefore, it is very important to prevent shivering during spinal anesthesia. The relative efficacy of interventions that are used for the treatment of postoperative shivering is not well understood. The origin of postoperative shivering is unclear; various mechanisms have been proposed. Shivering may happen as a thermoregulatory response to hypothermia or muscle hyperactivity with clonic or tonic patterns; and different frequencies have been reported. However, in the postoperative period, muscle activity may be increased even with normothermia, suggesting that other mechanisms than heat loss and subsequent decrease in core temperature may contribute to the development of shivering. These include uninhibited spinal reflexes and decreased sympathetic activity. Shivering is a frequent event during spinal anesthesia and meperidine is a wellknown effective drug for the prevention and treatment of shivering. Fentanyl is an opiate analgesic also known to have an anti-shivering effect. We compared fentanyl with meperidine for efficacy in the prevention of shivering during spinal anesthesia.

\section{METHODOLOGY}

This study was a prospective, double blind, randomized, controlled study. After the approval of the institute's ethics committee and obtaining written informed consents, 650 patients based on the American Society of Anesthesiologists physical status I or II, aged 40-75 years and scheduled for elective urologics surgery under spinal anesthesia were investigated. Patients with ASA physical status >II, Obesity (BMI $>28 \mathrm{~kg} / \mathrm{m} 2$ ), Parkinson`s disease, Rayaud's syndrome, ischemic heart disease or cerebrovascular disease requiring blood transfusion during surgery were excluded from the study. Patients were randomly divided into two groups; meperidine (Group M, n =325) and fentanyl (Group F, n = 325 ) groups. Group $M$ and $F$ received meperidine $0.4 \mathrm{mg} / \mathrm{kg}$ or fentanyl $1.5 \mathrm{mcg} / \mathrm{kg}$, respectively, in $100 \mathrm{ml}$ of isotonic saline intravenously. Preparation of physiological sol with petidine or fentanyl was made by a nurse. Meanwhile the anaesthesist was not in the know of what the patient had taken; petidine or fentanyl. All drugs were infused for 15 min by a blinded investigator before spinal anesthesia. The ambient temperatures of the operating rooms were maintained at $22^{\circ} \mathrm{C}$ and no active warming for patients was used. All patients received $5 \mathrm{ml} / \mathrm{kg}$ of lactated Ringer's solution before spinal anesthesia without any premedication. Temperature in the surgery room was kept 21-22 ${ }^{\circ} \mathrm{C}$. The solutions which were perfused on the patients have been on room temperature. Spinal anaesthesia was pulled off on sitting position, in space L2L3 or L3-L4. Sol mercaine $0.5 \%-3 \mathrm{ml}(15 \mathrm{mg})$ was injected using a needle 24-25-26-G. Spinal anesthesia was performed with a 24-25-26G Quincke spinal needle between the L2-L3 or L3-L4 interspinal space in the sitting position and $15 \mathrm{mg}$ of $0.5 \%$ hyperbaric bupivacaine was injected intrathecally. Bupivacaine doses, sensory block levels and durations of surgery were checked, and mean blood pressures, heart rates, were measured before (baseline) and at 15, 30, and $60 \mathrm{~min}$ after spinal anesthesia. Sensory block levels were tested by using alcohol swabs every 5 minutes after intrathecal injection to find maximal heights of sensory block. Also, sedation scores and shivering scores were checked till $60 \mathrm{~min}$ after spinal anesthesia. Shivering score was graded as; $0=$ no shivering, $1=$ slightly shivering, $2=$ muscle shivering, and $3=$ severe muscle shivering. Side effects such as hypotension, nausea and vomiting, pruritus, respiratory depression ( $\mathrm{SpO} 2<95)$ were observed. Hypotension was defined as a decrease in mean blood pressure of more than $20 \%$ from the baseline and was checked and treated with ephedrine $4 \mathrm{mg}$ repeatedly if it occurred. The incidences of side effects and scores of shivering and sedation scales were analyzed with the chi-square test. Bradicardia is corrected with atropine if the blood frequency falls less than $50 / \mathrm{min}$. It is considered hypotension if there has been a $20 \%$ decrease of basic MAP, which is measured before surgery. Hypotension was corrected with ephedrine, and nausea with metoklopramide $10 \mathrm{mg}$.

\section{Statistical analyses}

Statistical analysis of data was performed using SPSS software. Continuous variables were compared by means of t-test. Chi square was used to compare the proportions between variables and Mann Whitney test was used to compare scores between groups. Statistical significance was set at $p \leq 0.05$. All tests were two TAILED.

\section{RESULTS}

Table 1 shows the duration of the surgery was $75.8 \pm 48$ in the meperidine group and $78.5 \pm 50.8$ in the fentanyl group. The average age varied from $50.5 \pm 17.2$ in the meperidine group to $49.9 \pm 17.8$ in the fentanyl group.The average weight in the meperidine group was $65.9 \pm 12.81$ and $68.9 \pm 12.5$ in the fentanyl group.

No difference was observed between the two groups with regard to baseline characteristics for example, age, weight and the health status of the patients as well as the length of surgical procedures. The incidences and scores of shivering were not similar between the two groups. Shivering was observed in 15 (4.61\%) patients who received meperidine while in the fentanyl group, shivering occurred in 108 patients (33.2\%). In comparing the meperidine group with the fentanyl group, it was seen that preventing intraoperative and postoperative shivering in recovery without increasing side effects was significant $(\mathrm{P}<0.001)$. Blood pressure, body temperature and arterial oxygen saturation did not have a clinically significant change and were not different between the two groups. Side effects of 
Table 1. Demographic data variables in the two groups

\begin{tabular}{lcccc}
\hline \multirow{2}{*}{ Parameter } & Group M & Group F & test & P \\
\cline { 2 - 4 } & \multicolumn{4}{c}{ Mean (士S.D.) } \\
\hline Age (year) & $50.5 \pm 17.2$ & $49.9 \pm 17.8$ & $\mathrm{t}=-0.12$ & 0.7 \\
Gender (M/F) & $300 / 25$ & $303 / 22$ & $\chi^{2}=0$ & 0.8 \\
Weight (kg) & $65.9 \pm 12.8$ & $68.9 \pm 12.5$ & $\mathrm{t}=0.27$ & 0.5 \\
Height (cm) & $165.8 \pm 8.5$ & $168 \pm 8.8$ & $\mathrm{t}=0.14$ & 0.6 \\
ASA (I-II) & $125 / 200$ & $150 / 175$ & $\chi^{2}=0$ & 0.5 \\
Duration of surgery(min) & $75.8 \pm 48.5$ & $78.5 \pm 50.8$ & $\mathrm{t}=-0.19$ & 0.5 \\
\hline
\end{tabular}

Data are medians (ranges). Group M (Group meperidine) and Group F (Group fentanyl).

Table 2. Incidences of side effects

\begin{tabular}{lcc}
\hline Side effect & Group M & Group F \\
\hline Pruritus & $9(3)$ & $6(2)$ \\
Nausea & $22(6.8)$ & $16(5)$ \\
Respiratory depression & $0(0)$ & $0(0)$ \\
Sedation score $(n, 2,3,4)$ & $300 / 20 / 5$ & $298 / 15 / 12$ \\
Bradicardia & $32(10)$ & $39(12)$ \\
\hline
\end{tabular}

Values are number of patients (\%). Group M: meperidine group, Group F: fentanyl group. ${ }^{*} \mathrm{P}<0.001$, compared to Group M.

Table 3. Number of patients and points of peri-operative shivering

\begin{tabular}{|c|c|c|}
\hline $\mathbf{N}$ & Group M & Group F \\
\hline 0 & $250 *$ & 23 \\
\hline 1 & 60 & 85 \\
\hline 2 & 10 & 58 \\
\hline 3 & 3 & 35 \\
\hline 4 & 2 & 15 \\
\hline
\end{tabular}

opioids were unremarkable (Table 2). Meperidine infusion in the perioperative period significantly reduced shivering associated with spinal anaesthesia in urologic procedures that fentanyl infusion in the perioperative period.

\section{DISCUSSION}

Various drugs have been used to treat or prevent postoperative shivering, but the ideal treatment is yet to be determined. Pharmacological therapies such as tramadol, physostigmine, clonidine, ketamine, $\mathrm{MgSO}_{4}$ and petidina have been used to prevent shivering (Buggy et al., 1997; Schwarzkoph et al., 2001). While most thermoregulatory drugs including meperidine reduce both the thresholds of shivering and vasoconstriction (Alfonsi et al., 2004). As indicated above, there is evidence that pethidine may act via kappa opioid receptors in the treatment of this condition. Fentanyl also binds to kappa receptors, although five -fold more weakly than petidine when binding to mu opioid receptors when used as a reference (Mangani et al., 1982). Post operation shivering is one of the unwanted and common complications. It is therefore encouraging that some simple and inexpensive interventions are effective in the treatment of the adverse effect of anesthesia and surgery. It is possible, therefore, that fentanyl when given in a relatively high dose, acts via kappa receptors to stop postanaesthetic shivering(Table 3).

Meperidine was introduced as an antispasmotic drug in 1939 and is central to many PAS protocols (Latta et al., 2010). It is a well-known drug, familiar to most medical staff and possesses a reputation as a modality for the treatment of pain and shivering and has been readily available in the past. Research has provided abundant 
documentation regarding meperidine's potent antishivering effects; however, the mechanism for these effects is poorly understood. This drug exerts its action on $\mathrm{K}$-opioid receptors (KOR) and $\mu$-opioid receptors (MOR), whereas pure $\mu$-agonists such as fentanyl and morphine only work on MOR (Dewitte and Sessler, 2002; ISMP, 2004). KOR and MOR are types of opioid receptors which bind in order to exert their action. KORs are widely distributed in the brain (hypothalamus, periaqueductal gray, and claustrum), spinal cord (substantia gelatinosa) and in pain neurons. Researchers know meperidine treats PAS better than pure $\mu$-agonists, but can only speculate about the reason (Dewitte and Sessler, 2002; ISMP, 2004). This drug exerts its action on $\mathrm{K}$-opioid receptors (KOR) and $\mu$-opioid receptors (MOR), whereas pure $\mu$-agonists, such as fentanyl and morphine, only work on MOR. KOR and MOR are types of opioid receptors where opiates bind in order to exert their action.

The Institute for Safe Medication Practices Canada (ISMP Canada) issued a safety bulletin on meperidine (ISMP, 2004). In this 2004 publication, ISMP Canada recommended healthcare facilities evaluate the use of meperidine and limit this drug's use to the treatment of postoperative shivering, short term pain, and prevention/treatment of drug-induced or blood productinduced rigors. As the dictum says, "prevention is better than cure", it holds true for shivering also and it should be practiced.

The temperature regulating system of mammals is divided into three components: thermo-sensors and afferent neural pathways, integration system of thermal inputs, and effector pathways (autonomic and behavioral). The lateral spinothalamic tract is the main afferent pathway, projecting to the hypothalamic regulatory center and nuclei in the pons and midbrain. There is a modulation of neural transmission by the nucleus raphe magnus (inhibitor) and locus subcoeruleus (facilitator). The efferent pathway which begins in the hypothalamus, makes multiple connections with the reticular formation in the midbrain, pons, and medulla, and ends at the alpha-motor neurons. The main reactions activated by efferent pathways in response to hypothermia are vasoconstriction, nonshivering thermogenesis (described in neonates) and shivering (Ciofolo, 1989). Shivering is an oscillatory and involuntary muscle contraction that increases metabolic heat production. In addition to heat, there is marked increase in oxygen consumption and carbon dioxide production (Crowley and Buggy,2008) with potential risk of complications in patients with cardiovascular or pulmonary impairment. Neuro-axial block causes loss of thermoregulation below the level of blockage. Vasodilation occuring below the level of blockage is presumably responsible for body heat redistribution from the central compartment to the peripheral compartment.There is a normal shivering reflex in response to the drop in central temperature (Sessler, 2010).

\section{Conclusions}

We conclude that meperidine infusion in the periopertaive period significantly reduced shivering associated with spinal anaesthesia in urologic procedures. Meperidine is a better alternative than Fentanyl for preventing shivering in patients during spinal anaesthesia $(\mathrm{P}<0.001)$.

\section{Conflict of Interests}

The authors declare that there is no conflict of interests regarding the publication of the paper

\section{REFERENCES}

Alfonsi P, Adam F, Passard A, Guignard B, Sessler DI, Chauvin M (2004). Nefopam, a nonsedative benzoxazocine analgesic, selectively reduces the shivering threshold in unanesthetized subjects.Anesth. 100:37-43. Crossref

Buggy D, Higgins P, Moran C, O'Donovan F, McCarroll M (1997). Clonidine at induction reduces shivering after general anaesthesia. Can. J. Anaesth. 44:263-267.Crossref

Ciofolo MJ, Clergue F, Devilliers C, Ben Ammar M, Viars P (1989). Changes in ventilation, oxygen uptake, and carbon dioxide output during recovery from isoflurane anesthesia. Anesthesiology;70:737-741. Crossref

Crowley LJ, Buggy DJ (2008). Shivering and neuraxial anesthesia. Reg Anesth Pain Med. 33:241-252.Crossref

Dewitte J, Sessler DI (2002). Perioperative shivering. Anesthesiology.96:467-484. Crossref

DeWitte J, Sessler DI (2002). Perioperative shivering: physiology and pharmacology. Anesthesiol. 96:467-484.

ISMP Canada Safety Bulletin (2004). Meperidine: Issues in medication safety.; 4:8-10. Crossref

Latta KS, Ginsberg B, Barkin RL (2002). Meperidine: A critical review. Am. J. Ther. 9(1):53-68.Crossref

Mangan J, Paterson SJ, Tavani A, Kosterlitz HW (1982). The binding spectrum of narcotic analgesic drugs with different agonist and properties,Naunyn Schmiedebergs archives of Pharmacol:319:197-205.Crossref

Schwarzkoph KR, Holff H, Hartman M, Fritz HG (2001). A comparison between meperidine,clonidine,and urapidil in the treatment of postanaesthetic shivering. Anaesth Analg: 92:257-60.Crossref

Sessler DI (2008).Temperature monitoring and perioperative thermoregulation. Anesthesiology,;109:318-338.Crossref

Sessler DI (2010). Temperature regulation and monitoring.In: Miller RD, Eriksson LI, Fleisher LA, Wiener-Kronish JP, Young WL, eds. Miller's Anesthesia. 7th ed. Philadelphia, PA: Churchill Livingstone; pp.15331552. Crossref 